\title{
Using PET-G to Design an Underwater Rover Through 3D PrintingTtechnology
}

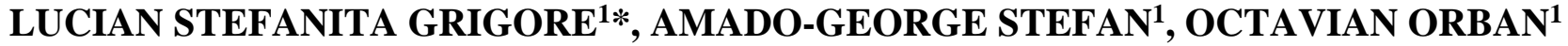 \\ ${ }^{1}$ Military Technical Academy Ferdinand I, Faculty of Communications and Electronic Systems for Defense and Security, \\ Department of Electronic Systems and Military Equipment, Center of Excellence in Robotics and Autonomous Systems \\ CERAS, 39-49 George Coşbuc Av., 050141, Bucharest, Romania \\ ${ }^{2}$ Military Technical Academy Ferdinand I, Faculty of Aircraft and Military Vehicles, Department of Integrated Aviation and \\ Mechanical Systems, 39-49 George Coșbuc Av., 050141, Bucharest, Romania \\ ${ }^{3}$ Military Technical Academy Ferdinand I, Faculty of integrated weapons, genius and mechatronics systems, Department of \\ Construction, Genetic Engineering and Geomatics, 39-49 George Coșbuc Av., 050141, Bucharest, Romania
}

Abstract: The development of 3D printing technologies has gained considerable momentum. Almost every technical-scientific field uses this technology. The technology of $3 D$ printing thermoplastic materials (or fusible filaments - FFF), is based on the realization of the parts by depositing successive layers of extruded filament at temperatures corresponding to the viscous aggregation state. One of the research activities of the CERAS research center is the realization of collaborative drone systems, drones capable of moving in each of the three unstructured environments: aerial, terrestrial aquatic / underwater. This paper presents a study on the choice of the type of thermoplastic material, for making the structural elements (chassis) of an underwater Rover. The need for this study arose from the fact that the design and construction of underwater vehicles is generally demanding. The materials must be characterized by resistance to compression / stretching / shearing, as in underwater environments the existence of currents, pressures (with increasing depth of immersion). Also, the materials must be chemically neutral, because in aquatic environments we can find various chemicals spilled in water (intentional or not) and finally salinity.

Keywords: Plastic material, 3D printing, PET-G, PLA, Fused filament fabrication FFF, Mathematical model, Experimental tests.

\section{Introduction}

The use of fusible filaments is a 3D printing technique [1], which allows the creation of a part of an assembly / subassembly layer by layer, by depositing the melted thermoplastic material through a nozzle. In this paper, the thermo-mechanical characteristics of two types of thermoplastic materials are studied: PET-G (Polyethylene Terephthalate - Glycol) and PLA (Polylactic Acid), used to make structural components of an underwater Rover MTA-ROUV (Military Technical Academy-Remotely Operated Underwater Vehicle) [2] (Figure 1).

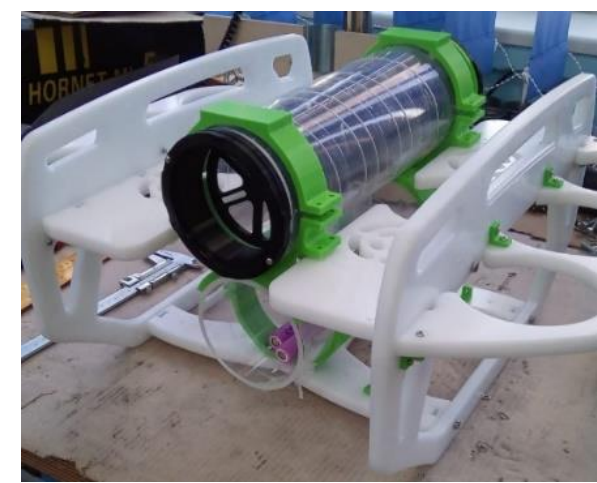

Figure 1. Rover MTA-ROUV

*email: lucian.grigore64@gmail.com 
The analyzes performed take into account the effects due to the type of internal structure, the degree of filling (infill), the size of the solid viscous material, usually $100 \mu \mathrm{m}$, which allows construction with dimensional accuracy [3-5]. According to [5] it is estimated that the mechanical properties of 3D printed parts form different mesostructured depending on the shape of the part, the temperature of the bed and the extruder. The printing principles [3] show how the dynamics of melt flow and temperature (printing bed, extruder) influences the extrusion process and the process of making connections between successive layers of material. These influences are manifested by the way in which the final interface between the "beads" is formed. This distance is also responsible for the way in which the next layers "stick" to each other, so that the thermo-mechanical characteristics can satisfy the real conditions of movement in an unstructured environment and in which the disturbing elements of the hydrodynamics are random.

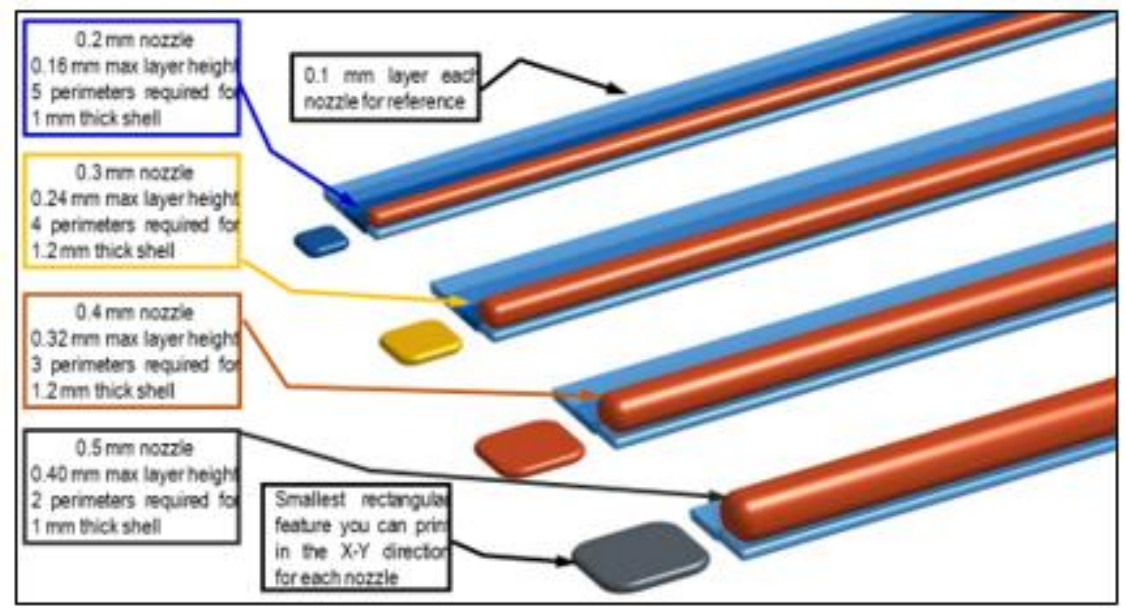

Figure 2. Diagram on the influence of nozzle diameter on layer adhesion [12]

Another aspect to be considered is the size of the nozzle hole of the extruder head (Figure 2). A larger diameter of the nozzle hole allows to increase the printing speed, but from the point of view of the adhesion of the layers, empty spaces can appear, and the adhesion should be at the tangent level of the mesostructured of the molten polymer. In this case the density of the gaps is quite high, and the tensile / compressive / shear strength can be reduced by up to $50 \%[9,10,43]$.

All this stipulates that at the mesoscale level the characteristics in the contact area can be reduced, so that the size of the nozzle hole must be reduced, but not randomly. The increase of the contact surfaces $[3,5,10,11,38]$ is considered to give very good results if the vacuum density is between $-5 \%$ and $-27 \%$ (1), depending on the direction of the efforts (Figure 3).

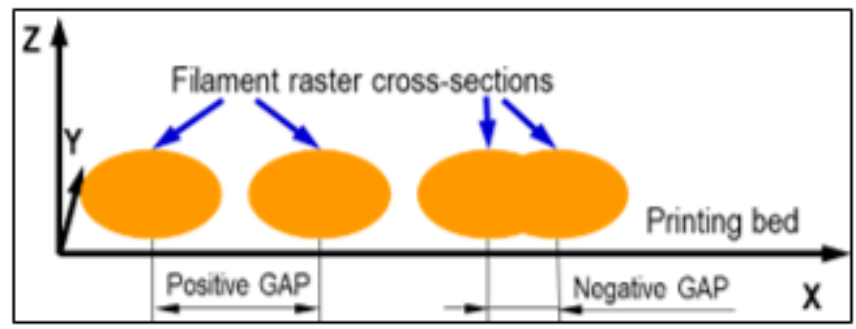

Figure 3. Diagram of the influence of nozzle diameter on layer adhesion [8], (Figure 5, pp. 5)

\section{Materials and methods}

\subsection{Analytical-numerical modeling}

The structural model involves an outer part, which is subjected to thermomechanical forces and loads and an inner part, which takes over the stresses due to external forces. At the mesoscale (threedimensional characterization to be able to model the structure's responses to thermal and mechanical 
loading) the contact area between the printed parts and the reduction of the content (infill) may show structural changes, as the two parts differ geometrically and dimensional $[5,8]$.

Tensile and compressive strength tests $[8,13,39]$ have shown that the characteristics of the printed material are influenced by the following parameters: filament air gaps [14], humidity, preheating temperature, angle and distance between scrapers and the size of the circumferential connection between the fiber and the fiber (2) depending on the density of the fiber interface link length [10].

In order to carry out the tests, it was decided that the test samples (specimens) will be made of PLA and PETG monofilament with a diameter of $1.75 \mathrm{~mm}, 4 \mathrm{~mm}$ nozzle, the material was removed from the packaging with desiccated (silica gel) before the operation printing [10,14].

$$
\begin{aligned}
\rho_{i} & =\frac{\text { Void Area }}{\text { Cross Section Area }}, \\
\text { B.L.Density } & =\frac{\sum \text { Fiber Bond Lengths }}{\text { Total Circumference Length }} .
\end{aligned}
$$

The modeling of mechanical structures takes into account that the molten material is laid layer after layer as in a rolling process [11], so that one can appreciate the existence of two levels: one macro (layer by layer) and one micro (molecular structure and gap density). After the semi-molten material (first layer) is deposited on the work bed, it begins to cool and stick (diffusion) to the neighboring material (thermodynamic processes). Subsequently, the diffusion of the semi-molten material is much better as it combines with a semi-cooled material, with identical physical and chemical properties. Each raster can be geometrically modified by the flow of semi-molten material that is pushed through the nozzle. Each layer can be deposited controlled independently, so that overlaps of unidirectional layers, contour, etc. can be obtained (Figure 4) [15]. The basic relationships used in the design of the structures for the components of the ROUV in order to identify the thermo-mechanical behavior take into account the orientation of the filament (raster) according to the direction of loading and the longitudinal direction corresponding to each rolling.

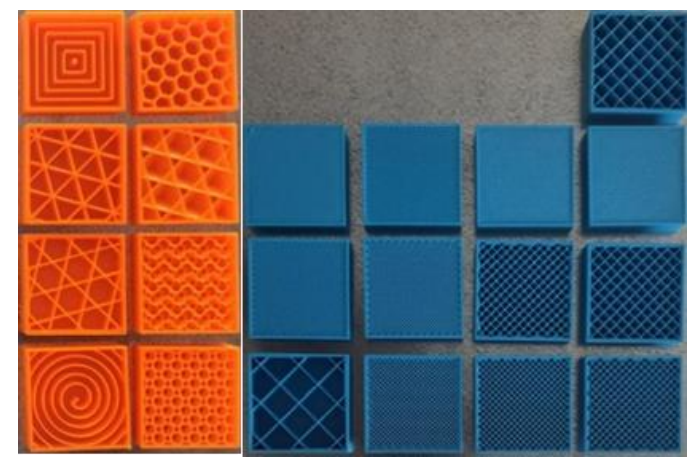

Figure 4. Types of infill shapes, sizes, patterns used

for interior filling of printed parts. The correctly chosen filling contributes to obtaining an optimal rigidity, depending on the purpose. PRUSA [15]

The relations for the ortho-tropical case (3), where $\theta=0^{\circ} / 90^{\circ}$, are reduced to the following form of equation:

$$
\left[\begin{array}{l}
\sigma_{11} \\
\sigma_{22} \\
\sigma_{12}
\end{array}\right]=\left[\begin{array}{ccc}
Q_{11} & Q_{21} & 0 \\
Q_{21} & Q_{22} & 0 \\
0 & 0 & Q_{33}
\end{array}\right] \cdot\left[\begin{array}{l}
\varepsilon_{11} \\
\varepsilon_{22} \\
\varepsilon_{12}
\end{array}\right],
$$

where: $\left[\sigma_{i j}\right]$ - represents the mechanical stress in the plane; $\left[\varepsilon_{i j}\right]$ - deformation in the plane; $[Q]$ - is the stiffness matrix. In order to be able to describe the behavior of the material in the elasto-plastic field, we 
will also take into account the following four modules: $\left[E_{11}\right]$ - Young's longitudinal module; $\left[E_{22}\right]$ Young's transversal module; $\left[v_{12}\right]$ Poisson's report; $\left[G_{12}\right]$ - shear module. All elements in the matrix are functions of these constants. The elements of the matrix $[Q]$ are functions of the four independent elements [16-19]. Considering a thermo-mechanical stress, in the numerical modeling of the polymer sintering processes, heat transfer relations were used [20]. From the study [21-24] it was found that the extruded material cools, under certain conditions, much faster than it should, so that structural detachments will occur. Therefore, measures have been taken to achieve an energy balance between surface tension and energy dissipation (for viscous material). The existence of variable parameters implies the use of predictive models. It is considered [24] that the radius of the extruded particle varies during the rolling and bonding processes with the adjacent layers (Figure 5).

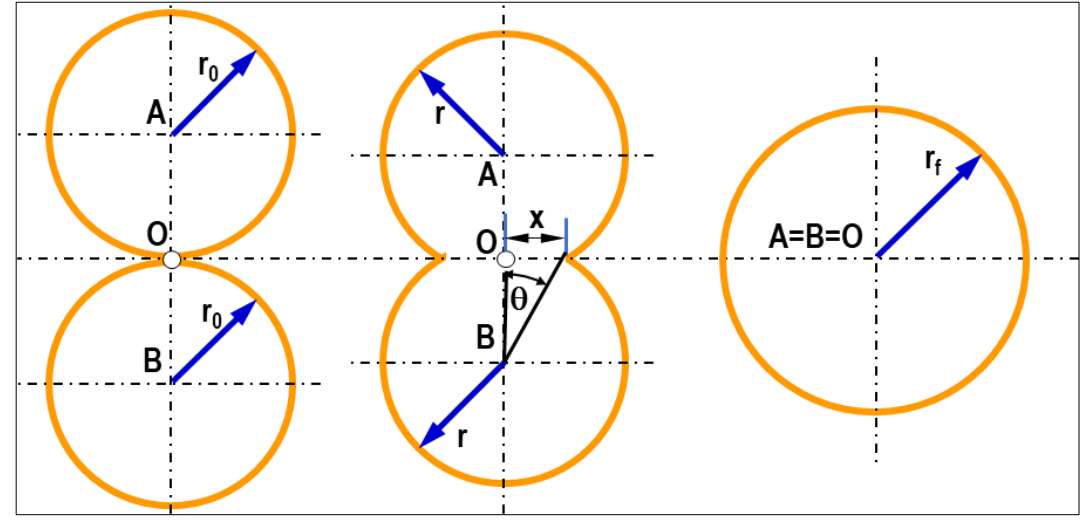

Figure 5. Evolution of the shape of the extruded filament, depending on the surface tension of the viscous material [24] (Figure 1 pp. 3253)

The model shown in (Figure 5) does not take into account other forces, including gravitational. The evolution, over time, of the shape of the spheres (related to the beads) is due to the principle of conservation of mass, under conditions of constant density (4). At time $t=0$ two spheres "A" and "B" with radius $r_{0}[\mathrm{~mm}]$ are in contact at point "O". After $t[\mathrm{~s}]$ both centers moved to the contact point "O"; resulting in a new geometric configuration characterized by an angle $\theta(t)$ [rad] of intersection of the spheres and a radius $r(t)$ of the "bottleneck" portion. Finally, the two spheres merge, so that the centers join with the "O" point. The model does not take into account other forces, including gravitational.

$$
r(t)=r_{0} \cdot\left(\frac{4}{\{1+\cos [\theta(t)]\}^{2} \cdot\{2-\cos [\theta(t)]\}}\right)^{\frac{1}{3}}[\mathrm{~mm}],
$$

Heat transfer functions require the determination of the transfer surface, therefore [27] we have:

$$
S=4 \cdot \pi \cdot r^{2} \cdot[1+\cos \theta(t)]=\frac{8 \cdot \pi \cdot r_{0}^{2} \cdot 2^{\frac{1}{3}}}{[1+\cos \theta(t)]^{\frac{1}{3}} \cdot[2-\cos \theta(t)]^{\frac{2}{3}}}\left[\mathrm{~mm}^{2}\right],
$$

The nozzle during the extrusion process influences the liquefaction of the plastic. 


$$
\left\{\begin{array}{c}
\tau=\left(\frac{\dot{\gamma}}{\phi}\right)^{\frac{1}{m}} \\
\Delta p=\left[\frac{(m+3) \cdot(2 \cdot L)^{m} \cdot \dot{Q}}{\pi \cdot R^{m+3} \cdot \phi}\right]
\end{array}\right\} \text { Tubes }
$$

The diameter and the internal transition angle of the nozzle (usually 1200) lead to the appearance of vortices (dead zones in the extrusion process) [26]. These vortices are responsible for creating flow instabilities and even in-foundation of the nozzle. Reducing the opening angle of the nozzle could lead to reduced vertices but will increase shear efforts and the pressure will decrease. These undesirable effects are due to the Reynolds number, which differs depending on the flow section [27].

The pressure loss in a conical convergent tube can be represented as the sum of the discrete pressure losses of the infinitesimal equivalent tubes connected in series and with the contraction in diameter, as follows. There is a very wide range of filament plastics that are used for 3D printing. Each of them has thermo-mechanical characteristics and properties, so that the choice of one of them must be made according to the analytical-numerical models and their verification with the values obtained after testing. For MTA-ROUV we chose to test two types of materials:

- PLA - is a thermoplastic polyester, whose chemical formula is $\left(\mathrm{C}_{3} \mathrm{H}_{4} \mathrm{O}_{2}\right) \mathrm{n}$, being one of the most common materials, but has many physical and processing deficiencies;

- $\quad$ PET-G - is a thermoplastic polyester, whose chemical formula is $\left(\mathrm{C}_{10} \mathrm{H}_{8} \mathrm{O}_{4}\right)$, it is also a widely used material.

To determine the heat flux, it is assumed that: the previously deposited material has cooled to equilibrium temperature; the thickness of the thermal field is an average; heat transfer from the anterior and current layers is modeled on the principle of thermal radiation. Thus, the system of equations (convection) is described in two dimensions:

$$
\left\{\begin{array}{l}
\rho \cdot c_{p} \cdot V \cdot \frac{\partial T}{\partial x}=\frac{\partial}{\partial x}\left(k \cdot \frac{\partial T}{\partial x}\right)+\frac{\partial}{\partial y}\left(k \cdot \frac{\partial T}{\partial y}\right)-\frac{h_{\infty}}{t \cdot h} \cdot\left(T-T_{\infty}\right)-U \cdot\left(T-T_{\text {sub }}\right) \\
T=T_{0},(\forall) \vec{r} \in \Gamma_{1} \\
T=T_{\text {sub }},(\forall) \vec{r} \in \Gamma_{2} \\
-k \cdot \frac{\partial T}{\partial n}=\frac{h_{\infty}}{t \cdot h} \cdot\left(T-T_{\infty}\right),(\forall) \vec{r} \in \Gamma_{3} \\
\frac{\partial T}{\partial n}=0,(\forall) \vec{r} \in \Gamma_{4}
\end{array} .\right.
$$

The study of the physical-chemical-mechanical characteristics of the two types of materials, aims to choose the most suitable material to achieve ROUV. Being a solid structure, which is not full on the inside (infill $15 \div 30 \%$ ), we can say that both the shape of the outer and inner surfaces determines the evolution of efforts during the tests.

Both filaments belong to the polyester group of plastics, which means that they soften above a certain specific temperature and become solid once they cool. The two materials, however, differ in terms of physical and chemical properties. PETG compared to PLA has a higher mechanical strength, resists very 
well to UV (ultraviolet), does not decompose in contact with liquids or chemicals. In the presence of vapors of acetone or plexiglass acrylic or PMMA (Poly Methyl Methacrylate), it may change its elasticity when the requirements for use involve a higher index of elasticity. The finite element method was used to theoretically investigate the behavior of the parts and highlighted the total plastic deformation of the specimens. In order to experimentally verify the theoretical considerations, an orthogonal Taguchi design was made [30]. The empirical mathematical model thus determined highlighted the stronger influence exerted by the temperature of the printing plate, the printing speed and the wall thickness.

\subsection{Considerations for tensile testing in order to choose the material for 3D printing}

In order to determine which materials, according to the geometric structure, are to be used, test specimens are prepared in order to perform tensile testing of the mechanical properties of the parts obtained by the 3D Printing method, taking into account the specifications described in ISO 527-1: 2019 (E), ISO 527-2: 2019 (Tensile Testing for Plastics) was taken into account for the choice of test specimens. In [29-32] the tested raster models and the conclusions obtained are described quite well. Therefore, the solutions adopted in the form of cross lines are the model that best responded to mechanical testing. Other raster models have generated stress concentration points.

The PLA characteristics according to [19], (Table 1), present values for the maximum load related to the elasticity area, taking into account the variation: wall thickness, printing speed, extruder cooling conditions and printing bed temperature.

The PETG characteristics according to $[7,33,42]$, present values for the maximum load related to the elasticity area, taking into account the variation: wall thickness, printing speed, extrusion cooling conditions and printing bed temperature. From what is presented, it is concluded that the chassis elements of ROUV are better to be made, through 3D Printing technology, from PETG.

\section{Results and discussions}

Figure 6 shows the set of plexiglass cylinders containing the electronic command and control $[37,40]$ part of the mini-submarine, which by means of plastic supports, semi-cylindrical, are attached to the chassis of the submarine (Figure 7). The clamps of the two cylinders are similar, therefore only the top cylinder will be used for analysis. It contains a vertical center plate for supporting electronic components, a hemispherical dome at the front and a back cover through which the electrical wires pass.

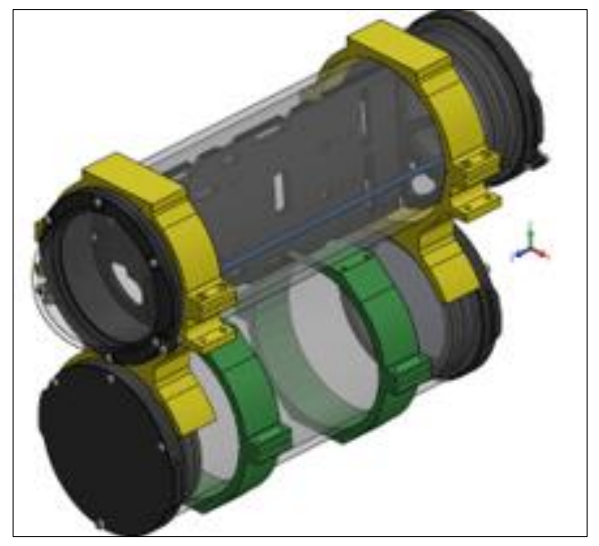

Figure 6. The assembly of the two cylinders: command/control components and accumulators

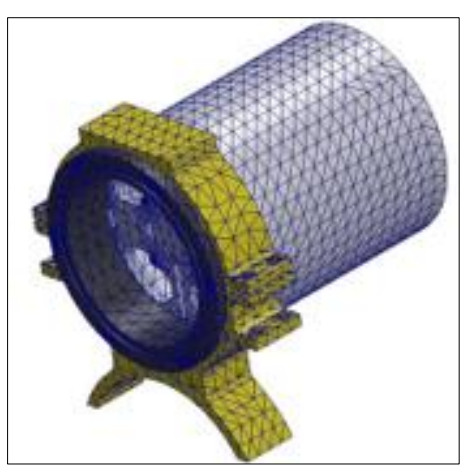

Figure 7. Positioning the cylinder assembly in the mini-submarine chassis

The component parts were made of ABS [41,43], with the properties: longitudinal modulus of elasticity $E=2[\mathrm{GPa}]$, tensile breaking stress $\sigma_{R}=30[\mathrm{MPa}]$, Poisson's ratio $\mu=0.394[-]$, and the plexiglass cylinder and dome: $E=3[\mathrm{GPa}], \sigma_{R}=72[\mathrm{MPa}]$ and $\mu=0.35[-]$. Tetrahedral elements were 
used to perform the discretization, with a maximum side size of 2.8 [mm], resulting in a few 1,011,008 [nodes] and 623,235 [elements] (Figure 8).

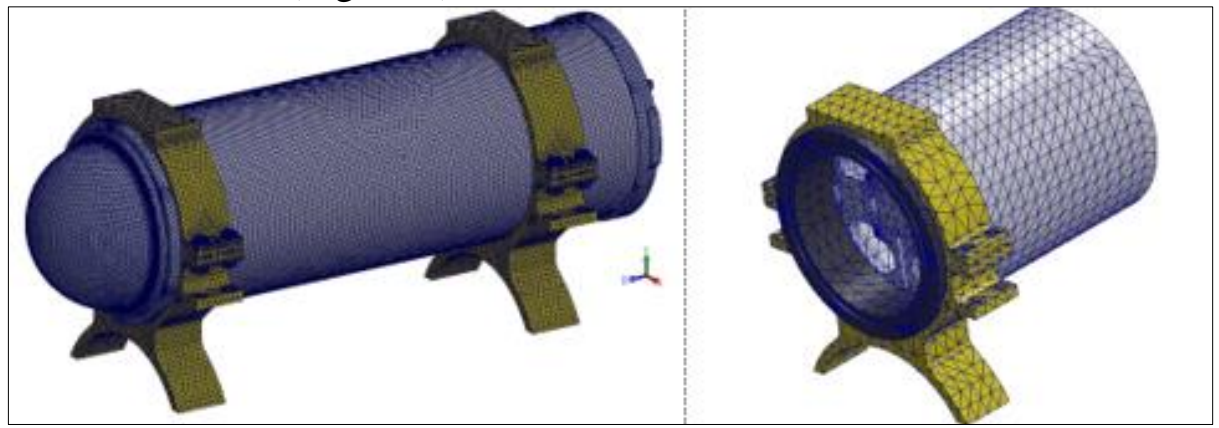

Figure 8. Discretization of the upper cylinder with tetrahedral elements

A first analysis was made during the assembly, when tightening the screws of the component parts, of the mini-submarine chassis. The plastic supports are forced by tightening by the screws to make a firm contact with the cylinder body. All screws are considered to have the same axial clamping force of $5[\mathrm{~N}]$ and the following conditions:

- for the nodes located on the surfaces of the holes in the supports where the chassis of the submarine (Figure 10) is connected, it is considered that we have no displacements;

- the contact between the component parts of the assembly is firm, except for the supports;

- the contact between the supports and the cylindrical body is without plastic deformations.

Following the analysis, for the whole set, the voltages (Figure 9) and the displacements (Figure 12) were determined.

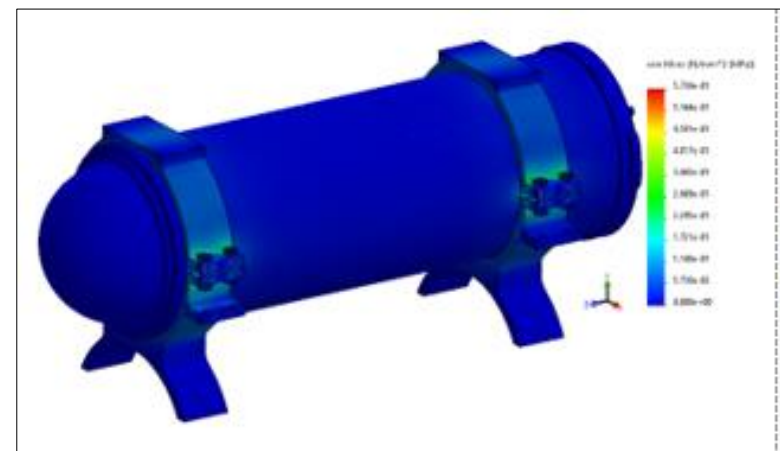

Figure 9. Von Mises tensions

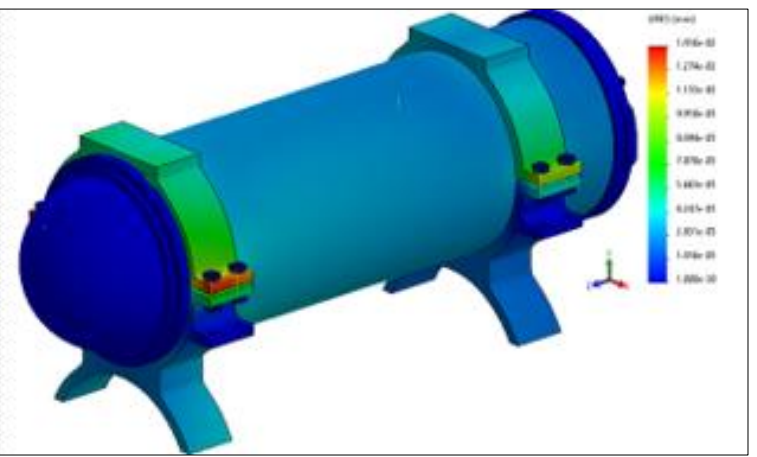

Figure 10. Nodal displacements

Figures 11a and b show the stresses in two cross-sections through the support adjacent to the dome, (a) - the sections through the middle of the support, (b) section containing the screw hole axis.

In the case of submarine diving, there are hydrostatic stresses for stationary operation and hydrodynamic stresses for the movement of the submarine. In the case of the mission, at a certain depth in stationary conditions, the cylinder assembly is subjected to hydrostatic pressure which is considered to act uniformly over the entire surface.

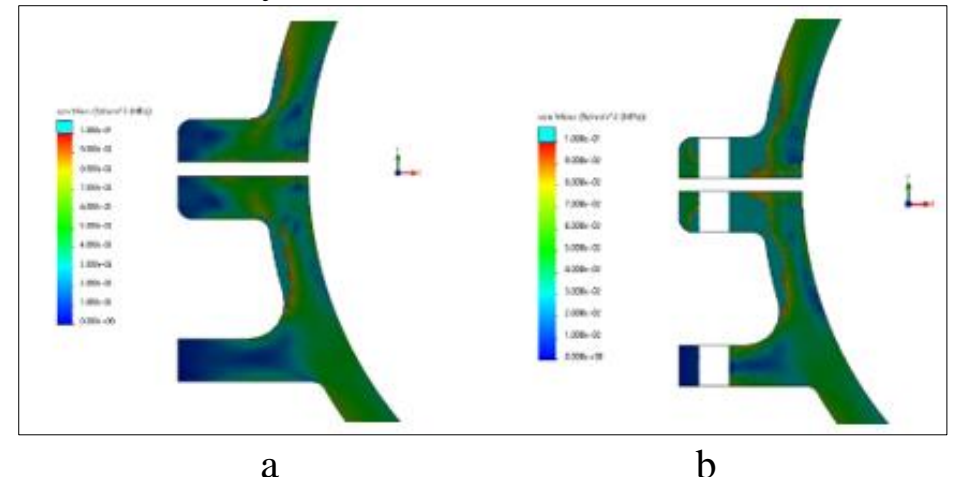

Figure 11. Tensions in the support adjacent to the dome - longitudinal 
Calculations were made for 3 depths: $30 \mathrm{~m}, 60 \mathrm{~m}$ and $90 \mathrm{~m}$, respectively. Figures 12-13 show: the field of equivalent stresses and displacements in general view, for the depth of $30 \mathrm{~m}$. In figures 14-15 are presented the results for $60 \mathrm{~m}$ depth and in Figures 16-17 those for $90 \mathrm{~m}$.

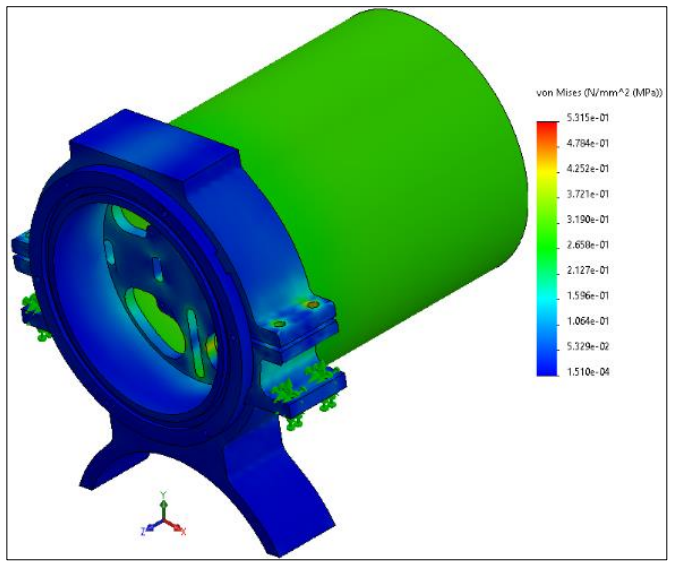

Figure 12. Von Mises Stress $30 \mathrm{~m}$

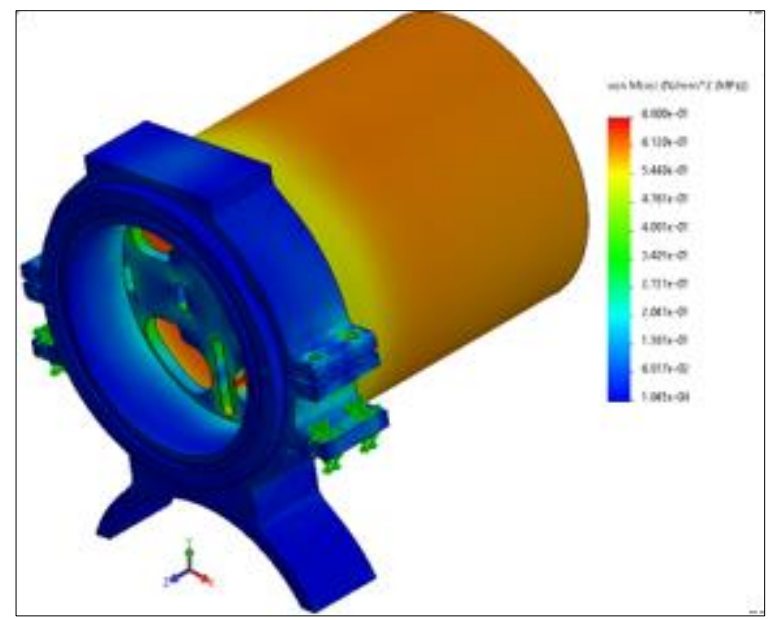

Figure 14. Von Mises Stress $60 \mathrm{~m}$

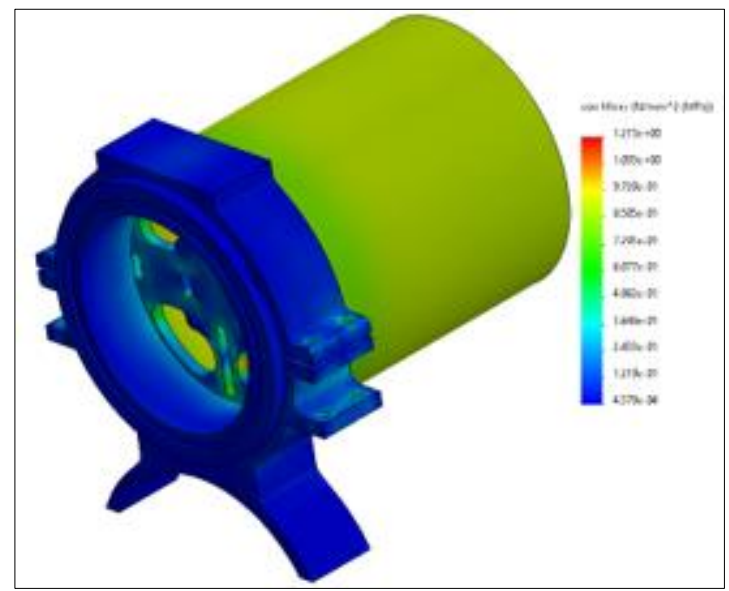

Figure 16. Von Mises Stress $90 \mathrm{~m}$

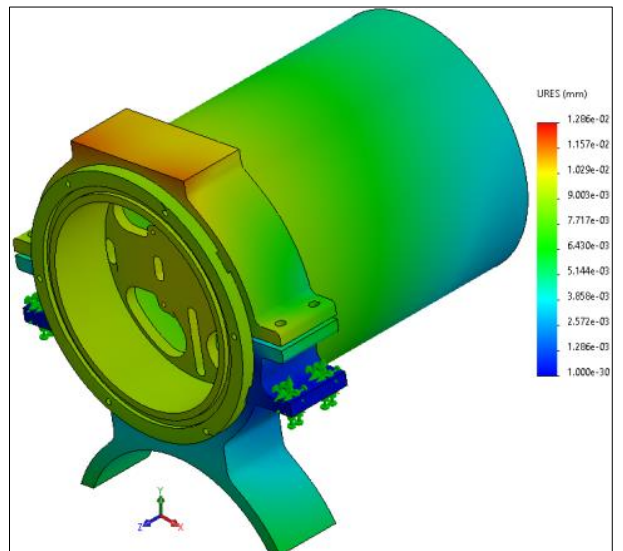

Figure 13. Nodal displacements $30 \mathrm{~m}$

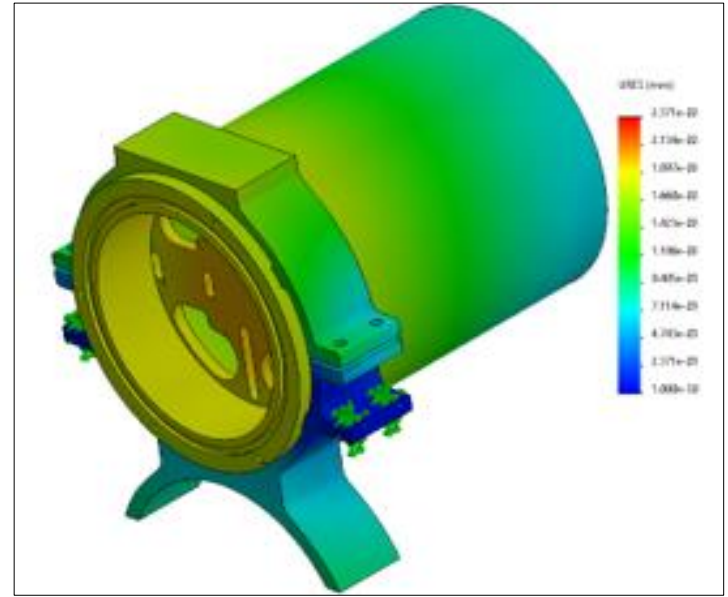

Figure 15. Nodal displacements $60 \mathrm{~m}$

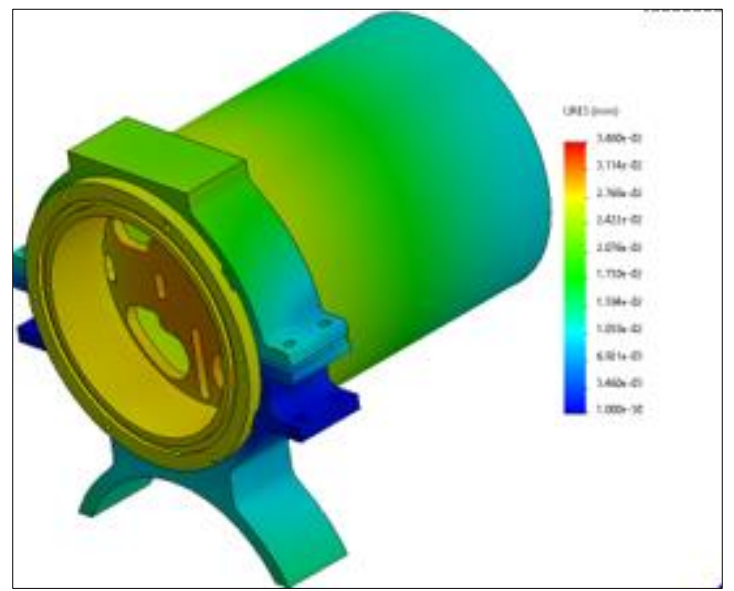

Figure 17. Nodal displacements $90 \mathrm{~m}$

There is an increase in equivalent stresses in all component parts of the system, especially in the cylinder body, the voltage reaching 1,215 MPa, at a depth of $90 \mathrm{~m}$, tension recorded on the outer surface of the cylinder in the area of tightening the plate, near the circular support interior of electronic equipment (Figure 18). 


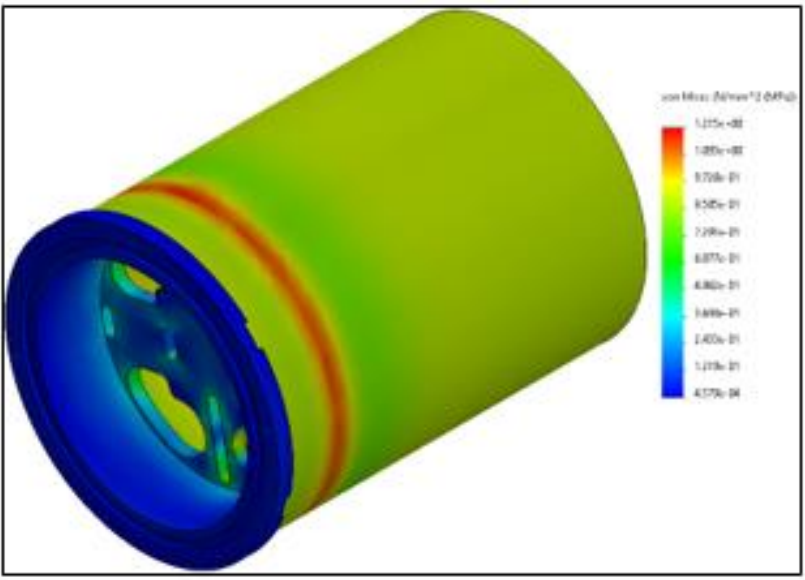

Figure 18. Equivalent stresses on the cylinder surface

In the flat band the tensions increase, but not very much, reaching the maximum value of $0.64 \mathrm{MPa}$, at a depth of $90 \mathrm{~m}$, being much lower than the breaking stress.

For the depth of $90 \mathrm{~m}$, the stability calculation indicates a safety factor of 2,4, the shape of the deformed being shown in section, in (Figures 19). It is found that the loss of stability would occur in the support plate of the electronic equipment, and later in the middle of the cylinder.

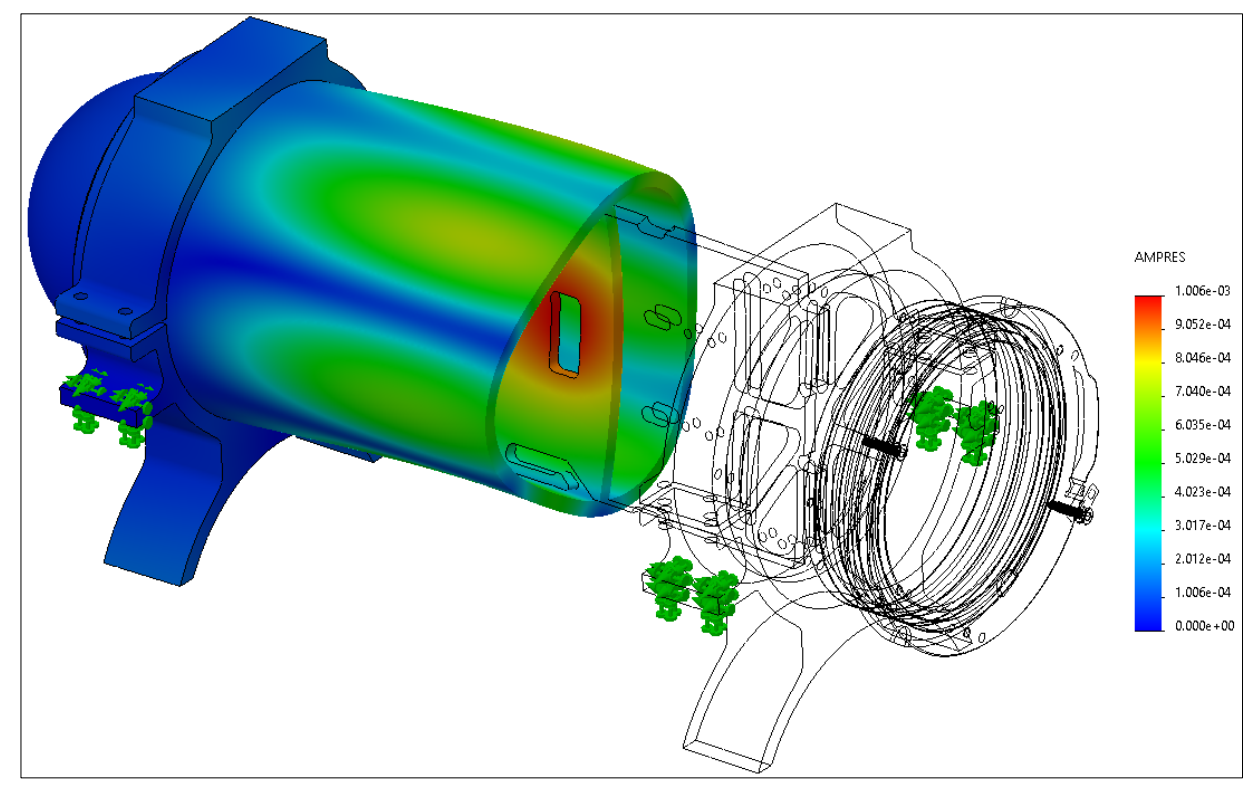

Figure 19. Deform shape - displacement field

This operating depth is structurally safe, and there may be leakage problems in the cylinder - cylinder area and in the plug - electrical areas, respectively. Sealing compromise leads to a loss of electronic equipment and consequently to mission failure.

Another aspect is the deformation of the cylinder under the action of hydrostatic pressure, which tends to decrease its diameter more in the central area than in the ends, where there are opposing circular supports. As a result, there is a flare of the cylinder towards the ends, which can compromise the tightness between the caps and the cylinder. The covers contain annular channels in which there are rubber seals. The tightness is ensured by the compression of the gaskets during assembly, and the deformation mode and the external pressure can lead to the flooding of the cylinder. 
The presence of flat bands prevents flare-ups and is therefore a beneficial contribution. A new constructive solution is to increase the length of the support plate of the electronic equipment, so that the second flat strip is close to the back cover.

\section{Conclusions}

PETG has some advantages over PLA: greater resistance to thermal degradation; greater thermal stability; a smaller statistical dispersion of PETG compared to PLA; increased flexibility in 3D printing.

Moreover, the way of assembling the ROUV components (modularity and Plug and Play), which will allow an easier access of the end users, following the analysis with MEF showed that it ensures a higher rigidity of the assembly compared to the basic model. The basic model is made of the same type of plastic.

The novelty of the study is the fact that integrated projects of autonomous mobile robots can be developed, starting from the design to the completion of the product, all within the research laboratories.

Acknowledgments: Thanks to the Military Technical Academy, Center of Excellence in Robotics and Autonomous Systems - CERAS, for making the project data avaible: „ERL Emergency project: UGV and ROUV'. We also thank the team members of the ROUV implementation: MOLDER, C., GORGOTEANU, D., CONSTANTIN, D., ȘTEFAN A., MOLDER (MILĂȘAN) A., STOICA, P., FOCȘA, A., and all.Another project for which we thank Military Technical Academy, Center of Excellence in Robotics and Autonomous Systems - CERAS, for making data avaible is ,Manufacturing specification for the product: Protective visor kit RC3/M2 - S.F.1", Nr. A3234/2020. We also thank the team members: MOLDER, C., CONSTANTIN, D., GORGOTEANU, D., MOLDER (MILĂȘAN) A., FOCŞA, A., STOICA, P., ANDREESCU, E.

\section{References}

1.BLOK, L.G., Longana, M.L., Yu, H., Woods, B.K.S., „An investigation into 3D printing of fibre reinforced thermoplastic composites" Additive Manufacturing, vol. 22, pp. 176-186, Aug. 2018, doi:10.1016/j.addma.2018.04.039.

2.MOLDER, C., GORGOTEANU, D., CONSTANTIN, D., and all, „ERL Emergency project: UGV and ROUV', Military Technical Academy, Center of Excellence in Robotics and Autonomous Systems CERAS, 2019-2021, https://ceras.mta.ro/.

3.TURNER, B.N., GOLD, S.A., ,A review of melt extrusion additive manufacturing processes: II. Materials, dimensional accuracy, and surface roughness". Rapid Prototyping Journal, vol. 21, issue 3, pp. 250-261, 2015, ISSN: 1355-2546, doi:10.1108/RPJ-02-2013-0017.

4.BELTER, J.T., Dollar, A.M., „Strengthening of 3D printed fused deposition manufactured parts using the fill compositing technique", PLoS One, 10(4), pp. 1-19, 16 April 2015,

doi:10.1371/journal.pone.0122915.

5.RODRIGUEZ, J.F., THOMAS, J.P., RENAUD, J.E., „Characterization of the Mesostructured of Fused-Deposition Acrylonitrile-Butadiene-Styrene Materials", Rapid Prototyping Journal, vol. 6, issue 3, pp. 175-186, 1 September 2000, doi:10.1108/13552540010337056.

6.BENWOOD, C., ANSTEY, A., ANDRZEJEWSKI, J., MISRA, M., MOHANTY, A., „Improving the Impact Strength and Heat Resistance of 3D Printed Models: Structure, Property, and Processing Correlation ships during Fused Deposition Modeling (FDM) of Poly (Lactic Acid)", American Chemical Society, ACS Omega, 3(4), pp. 4400-4411, 2018, doi:10.1021/acsomega.8b00129.

7.SZKIEDANS, K., CREDO, W., OSIŃSKI, D., ,, Selected mechanical properties of PETG 3-D prints”, The XXI International Polish-Slovak Conference "Machine Modeling and Simulations 2016", Procedia Engineering, 177(2017), pp. 455-461, doi:10.1016/j.proeng.2017.02.245.

8.CUAN-URQUIZO, E., BAROCIO, E., TEJADA-ORTIGOZA, V., BYRON, R., RODRIGUEZ C.A., ROMAN-FLORES, A., "Characterization of the Mechanical Properties of FFF Structures and Materials: A Review on the Experimental, Computational and Theoretical Approaches", MDPI Journal, Materials, vol. 12, issue 6, pp. 1-25, 18 March 2019, doi:10.3390/ma12060895. 
9.HUANG, B., SINGAMNENI, S., „Raster angle mechanics in fused deposition modelling”, Journal of Composite Materials, 49(3), pp. 363-383, February 2015, doi:10.1177/0021998313519153.

10.RODRIGUEZ, J.F., „Maximizing the strength of fused-deposition ABS plastic parts”, Conference „Proceedings 10th, Solid freeform fabrication symposium; 1999; Austin, Texas, USA”, Solid freeform fabrication symposium, pp. 335-342, SOLID FREEFORM FABRICATION PROCEEDINGS, 1999, ISSN: 1053-2153.

11.LI, L., SUN, Q., BELLEHUMEUR, C., GU, P., „Composite modeling and analysis for fabrication of FDM prototypes with locally controlled properties", Journal of Manufacturing Processes, vol. 4, issue 2, pp. 129-141, 2002, doi:10.1016/S1526-6125(02)70139-4.

12.MOU, Y.A., KOC, M., „Dimensional capability of selected 3DP technologies”, Rapid Prototyping Journal, vol. 25, issue 5, pp. 915-924, 2019, Emerald Publishing Limited, ISSN: 1355-2546, doi:10.1108/RPJ-03-2019-0061.

13.LEMU, H.G., KURTOVIC, S., „3D Printing for Rapid Manufacturing: Study of Dimensional and Geometrical Accuracy", Advances in Production Management Systems. Value Networks: Innovation, Technologies, and Management. APMS 2011. IFIP Advances in Information and Communication Technology, vol 384, PP. 470-479, 2012 Springer, Berlin, Heidelberg, ISBN: 978 3-642-33980-6, doi:10.1007/978-3-642-33980-6_51.

14.WANG, X., ZHAO, L., FUH, J.Y.H, LEE, H.P., „Effect of Porosity on Mechanical Properties of $3 D$ Printed Polymers: Experiments and Micromechanical Modeling Based on X-ray Computed Tomography Analysis", Polymers, 11(7), 1-20, July 2019, doi:10.3390/polym11071154.

15.***https://all3dp.com/2/, Available online: https://all3dp.com/2/infill-3d-printing-what-it-meansand-how-to-use-it/ (accessed on 31 May 2020).

16.MALLICK, P.K., „Fiber-reinforced composites: materials, manufacturing, and design”, Second Edition, Marcel Dekker, Inc., 1993, pp. 566, ISBN: 0-8247-9031-6.

17.RODRIGUEZ-MATAS, J.F., ,Modeling the mechanical behavior of fused deposition acrylonitrilebutadiene styrene polymer components", Thesis/dissertation, University of Notre Dame, 1999, pp. 396. 18.RODRIGUEZ, J.F., THOMAS, J.P., RENAUD, J.E., „Mechanical behavior of acrylonitrile butadiene styrene fused deposition materials modeling", Rapid Prototyping Journal, vol. 9, issue 4, pp. 219-230, 1 September 2003, ISSN: 1355-2546, doi:10.1108/13552540310489604

19.HRITUC, A., MIHALACHE, A., MAREȘ, M., COTEAȚĂ, M., DODUN, O., NAGÎT,, Gh., SLĂTINEANU, L., „Mechanical Behaviour of 3D Printed PLA Hollow Spherical Parts Under Axial Compression", Materiale Plastice Journal, vol. 57, issue 1, pp. 13-20, 17 April 2020, ISSN: 1355-2546, doi:10.37358/MP.20.1.5307.

20.DEVLIN, S.L., „Modeling of filament deposition rapid prototyping process with a closed form solution", Graduate Theses and Dissertations, 16121, pp. 161, 2017, https://lib.dr.iastate.edu/etd.

21.YARDIMICI, M.A., GUCERI, S.I., AGARWALA, M., DANFORTH, S.C., „Part quality prediction tools for fused deposition processing", Proceedings of the Solid Freeform Fabrication Symposium, University of Texas at Austin, pp. 539-548, August 1996.

22.YARDIMICI, M.A., HATTORI, T., GUCERI, S.I., DANFORTH, S.C., „Thermal analysis of fused deposition", Proceedings of the Solid Freeform Fabrication Symposium, University of Texas at Austin, pp. 689-698, ISSN: 1053-2153, August 1997.

23.BELLEHUMEUR, C., LI, L., SUN, Q., GU, P., „Modeling of bond formation between polymer filaments in the fused deposition modeling process", Journal of Manufacturing Processes, vol. 6, issue 2, pp. 170-178, 2004, doi:10.1016/S1526-6125(04)70071-7.

24.POKLUDA, O., BELLEHUMEUR, C., MACHOPOULOS, J., „Modification of Frenkel's model for sintering", American Institute of Chemical Engineers - AIChE Journal, vol. 43, issue 12, pp. 3253-3256, 17 June 1997, doi:10.1002/aic.690431213.

25.FRENKEL, J., „Viscous Flow of Crystalline Bodies Under the Action of Surface Tension”, Journal of Physics, Moscow, USSR, vol. 9, issue 5, pp. 385-390, 1945. 
26.LIANG, J.Z., LING, Y.Z., LI, R.K.Y., TIONG, S.C., „Quantitative description of vortical region length of non-Newtonian fluids through an abrupt contraction", ASME-AMD American Society of Mechanical Engineers, Applied Mechanics Division, vol. 217, pp. 105-107, ISSNs: 0160-8835, 1996. 27.MICHAELI, W., „Extrusion Dies for Plastics and Rubber: Design and Engineering Computations”, Publisher: München Carl Hanser Verlag, 2nd Edition, pp. 340, 1992, ISBN: 3446161902 9783446161900.

28.RAHUL, D., PRETESH, J., „Application of Taguchi-Based Design of Experiments for Industrial Chemical Processes", Statistical Approaches With Emphasis on Design of Experiments Applied to Chemical Processes, Valter Silva, IntechOpen, chapter 9, March $7^{\text {th }} 2018$,

doi:10.5772/intechopen.69501.

29.ĆWIKŁA, G., GRABOWIK, C., KALINOWSKI, K., PAPROCKA, I., OCIEPKA, P., „The influence of printing parameters on selected mechanical properties of FDM/FFF 3D-printed parts", IOP Conf. Series: Materials Science and Engineering 227 (2017) 012033 doi:10.1088/1757-899X/227/1/012033. 30.AHN, S.H., MONTERO, M., ODELL, D., ROUNDY, S., WRIGHT, P.K., „Anisotropic material properties of fused deposition modeling ABS", Rapid Prototyping Journal, vol. 8, issue 4, pp. 248-257, ISSN: 1355-2546, February 2000, doi:10.1108/13552540210441166.

31.WENDT, C., BATISTA, M., MORENO, E., VALERGA FERNÁNDEZ-VIDAL, A.P., DROSTE, S.R.O., MARCOS, M., „Preliminary design and analysis of tensile test samples developed by Additive Manufacturing", Procedia Engineering, 132, 132-139, 2015, doi:10.1016/j.proeng.2015.12.489.

32.BELLINI, A., GÜÇERI, S., „Mechanical characterization of parts fabricated using fused deposition modeling", Rapid Prototyping Journal, vol. 9, issue 4, pp. 252-264, ISSN: 1355-2546, October 2003, doi:10.1108/13552540310489631.

33.SANTANA, L., ALVES, J.L., NETTO, A.C., MERLINI, C., „A comparative study between PETG and PLA for 3D Printing through thermal, chemical and mechanical characterization", Revista Matéria, vol. 23, issue 4, pp. 252-264, article 12267, ISSN: 1517-7076, 6 December 2018, doi:10.1590/S1517707620180004.0601.

34.STOICA, P.M., MOLDER, C., "Comparative analysis of methods to detect radio-controlled commercial UAVs.", 4th International Scientific Conference SEA-CONF, 2018 Scientific Bulletin of Naval Academy 2018, Vol. XXI 2018, pg.45-49, doi:10.21279/1454-864X-18-I1-006.

35.GORGOTEANU, D., MOLDER, C., "Electric powered miniature vehicle for multi-agent network testbed.", Electric Vehicles International Conference, EV2019, 3-4 October 201, Bucharest, 978-17281-0791-2/19/\$31.00 @2019 IEEE, doi:10.1109/EV.2019.8892953.

36.TOMA, Ș.A., SEBACHER, B., FOCȘA, A., "On Anomalous Deformation Profile Detection Through Supervised and Unsupervised Machine Learning.”, July 2019 IEEE International Geoscience and Remote Sensing Symposium, doi:10.1109/IGARSS.2019.8898459.

37.PATRICIU, V., PRIESCU, I., NICOLAESCU, S., "Operational Security Metrics for Large Networks.”, Volume: I (2006), No: Suppl. Issue, International Journal of Computers, Comm\&Control (IJCCC) 2006, Oradea, pg 349-354, ISSN 1841- 9836; E-ISSN 1841-9844, 2006.

38.IFTIMIE, B., LUPOAE, M., ORBAN, O., "Experimental Investigations Regarding the Behaviour of Composite Panels Based on Polyurea and Kevlar or Dyneema Layers Under Blast and Fragments.", Mater. Plast., 56(3), 2019, 538-542.

39.ROTARIU, A., BUCUR, F., TOADER, G., LUPOAE, M., SAVA, A.C., SOMOIAG, P., CIRMACI MATEI, M., "Experimental Study on Polyurea Coating Effects on Deformation of Metallic Plates Subjected to Air Blast Loads", Mater. Plast., 53(4), 2016, 670-674

40.ROTARIU, T., ENACHE, C., GOGA, D.A., TOADER, G., STANCU, I.C., EŞANU, S., TRANĂ, E., "Theoretical and experimental studies on new plastic pyrotechnic compositions", Mater. Plast., 53(2), 2016, 240-246

41.BARZIC1, A.I., ALBU1, R.M., NECHIFOR, C.D., POSTOLACHE, M., LOGIGAN, C., DOROHOI, D.O., "Surface Processing of Polyethylene Terephthalate for Orientation of Nematics in Display Devices “, Mater. Plast., 57(2), 2020, 1-7. 
42.DRAGHICI, S., VINTILA, I.S., MIHALACHE, R., PETRESCU, H.A., TUTA, C.S., HADAR, A., "Design and Fabrication of Thermoplastic Moulds for Manufacturing CFRP Composite Impeller Blades", Mater. Plast., 57(1), 2020, 290-298.

43.NICOLA, I., TURCANU, D., PRISECARU, T., PREDOI, C., CIOBANU, M.C., "Natural Frequency Analysis of a ABS Material Drone Ground Moving System", Mater. Plast., 52(4), 2015, 568-571 